\title{
Myofascial Release improved Regional Kyphosis in a 20-year-old Female patient with Cervical Neuroforaminal Encroachment: A Case Report
}

\author{
Song-I $\operatorname{Han}^{\dagger} \cdot$ Jae-Man Park ${ }^{\dagger}$ \\ Department of Physical Therapy, Daejeon Barun mind Hospital \\ ${ }^{1}$ Department of Physical Therapy, Graduate of Graduate School, Daejeon University
}

Received: November 12, 2019 / Revised: November 26, 2019 / Accepted: December 12, 2019

(C) 2020 J Korean Soc Phys Med

\section{| Abstract |}

PURPOSE: This paper describes the effects of the myofascial release (MFR) approach in a 20-year-old female patient with neuroforaminal encroachment and regional kyphosis in the cervical area, who also had neck pain.

METHODS: A 20-year-old female presented with the chief complaint of neck pain while studying with a level of seven on the rating analogue scale (RAS) and was not taking any drugs or undergoing treatment for the control of neck pain prior to visiting. The cervical radiograph demonstrated neuroforaminal encroachment from C4-5. The patient showed $3.5^{\circ}$ kyphosis at $\mathrm{C} 4-5$ and $22.9^{\circ}$ lordosis at $\mathrm{C} 2-7$ according to the Harrison posterior tangent method. The anterior head translation (AHT) was $13.9 \mathrm{~mm}$. She reported pain of RAS 5 at the scapular medial border while rotating her neck in the left direction and flexing forward. The patient was treated a total 16 times, three times/week for six weeks using

$\dagger$ Corresponding Author : Song-I Han

ldpsk@@naver.com, https://orcid.org/0000-0001-7995-711X

This is an Open Access article distributed under the terms of the Creative Commons Attribution Non-Commercial License (http://creativecommons.org/licenses/by-nc/3.0) which permits unrestricted non-commercial use, distribution, and reproduction in any medium, provided the original work is properly cited. the MFR approach.

RESULTS: After the treatment sessions, studying without pain was possible for approximately two hours, but after approximately two hours of studying, she experienced pain of RAS 6 and a stiff feeling in front of the neck. Neuroforaminal encroachment was not detected in the radiographs taken after applying MFR. Improvement of C4-5 kyphosis was noted (from $3.5^{\circ}$ kyphosis to $3.8^{\circ}$ lordosis). AHT was decreased by $13.6 \mathrm{~mm}$ (from $13.9 \mathrm{~mm}$ to $0.3 \mathrm{~mm}$ ). The pain with motion had disappeared.

CONCLUSION: The MFR approach in this patient with neuroforaminal encroachment could reduce the pain related to motion and restore the regional cervical lordosis.

Key Words: Cervical alignment, Myofascial release, Neck pain, Neuroforaminal encroachment

\section{Introduction}

A narrowing of the intervertebral foramina due to intervertebral osteophytes may result in neuroforaminal encroachment that can cause cervical radiculopathy $[1,2]$. On the other hand, although a radiograph demonstrates encroachment due to intervertebral osteophytes, it does not 
indicate neck pain or radiating pain on the upper extremity most of the time [3].

Myofascial release (MFR) is an approach that focuses on the limitation of movement felt from the soft tissue of the body and is aimed at improving the suitability of the fascial tissue. Therefore, by providing mechanical stimulation as pressure in the site of the problem within the fascia network, the tissue alters the mechanical properties and potentially allows new mobility and organic mobility of the surrounding structures [4].

This paper describes the effects of the MFR approach on a 20-year-old female with neuroforaminial encroachment and neck pain.

\section{Methods}

\section{History of Subjects}

\section{1) Personal Information}

The patient was a 20-year-old female living in Daejeon, who was $163 \mathrm{~cm}$ in height and weighed $58 \mathrm{~kg}$. The patient was diagnosed with cervical fascia pain syndrome without neurological symptoms after screening from a clinician. The radiograph revealed neuroforaminial encroachment. She had not taken any drugs or undergone any treatment before visiting. After visiting the clinician, she received Eperinal Western Medicine, Stogae 10mg, Cetila 10mg, Pelubi Western Medicine twice a day for seven days in total.

\section{2) Chief Complain and Goal}

Her pain started one year ago as her level of study has increased. She complained of pain of RAS 7 along inside the scapula from the left posterior neck and stiffness in front of her neck with swelling on both sides above the scapula after approximately one hour of study with her head bowed forward to read a book. She had a pain level of RAS 2 while taking a break. In addition, she complained that there was pain at a level of RAS 3 on the internal side of her left arm approximately twice a month. She had not performed exercise. Her treatment goal was to increase the time for study.

\section{Measurement}

\section{1) Motion test}

The therapist examined the motion test. The pain of RAS 5 appeared at the scapular medial border during neck left rotation and forward flexion.

\section{2) Cervical Posture}

The cervical posture was measured by anterior head translation (AHT) and for the absolute rotation angle (ARA) for cervical lordosis using the internal measurement program of the Medical Image Information System (PACS). AHT was measured as the horizontal distance of the posterior superior body corner of $\mathrm{C} 2$ compared to a vertical line originating at the posterior inferior body corner of $\mathrm{C} 7$ at the sagittal plane of the radiograph. The cervical lordosis was measured using the Harrison posterior tangent method, which is a method for measuring the ARA between the lines following the two vertebral posterior margins; a positive and negative value means kyphosis and lordosis, respectively [5]. The therapist measured the regional lordosis to ARA between C4-C5 and global lordosis to ARA between C2-C7.

In the patient, AHT, global lordosis, and regional lordosis were $13.9 \mathrm{~mm},-22.9^{\circ}$, and $3.5^{\circ}$, respectively (Fig. 1).

\section{3) Myofascial Release Approach}

The patient was treated with the MFR approach by a physical therapist with ten years' experience, who is a regular member of the Korean Society of MFR. MFR was performed with reference to Smith's practical book, which was a direct approach based on Rollfing [4] and was performed on the patient for fifty minutes. Treatment was 

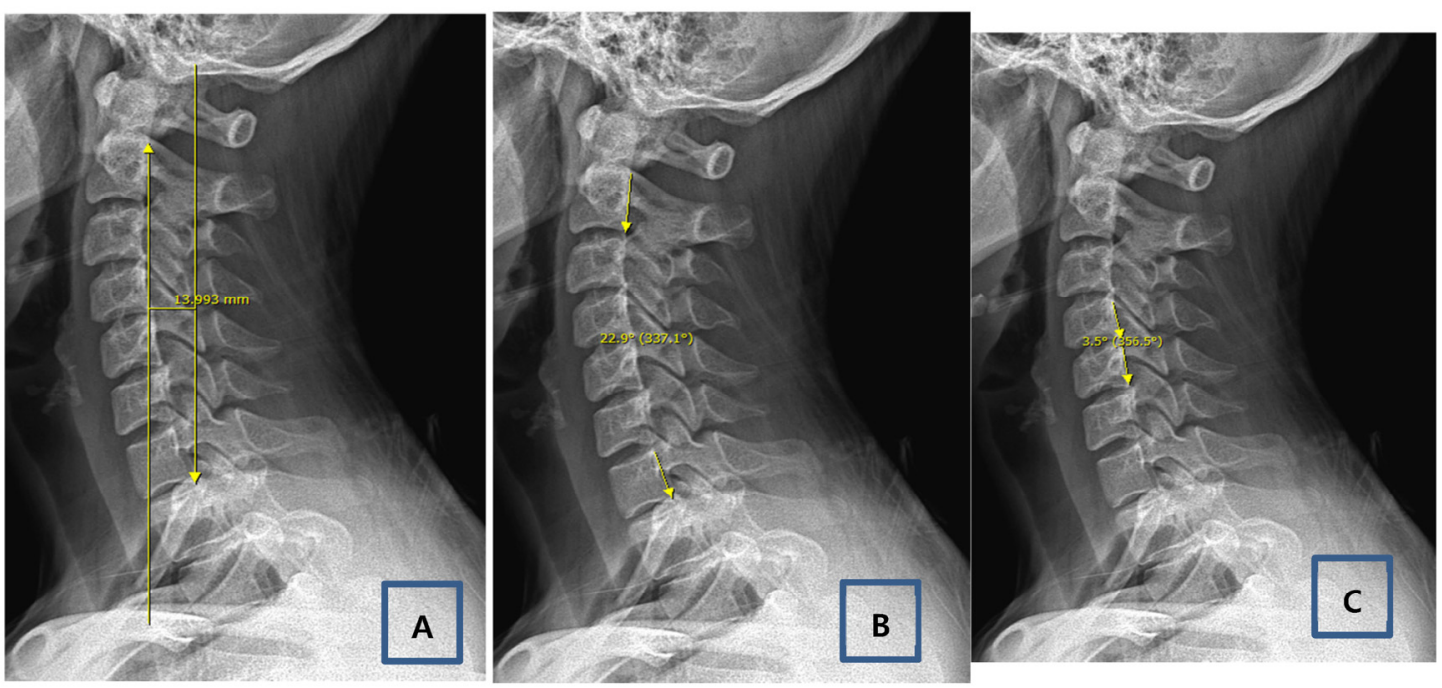

Fig. 1. Lateral projection of a cervical spine radiograph before treatment of MFR.

(A) Anterior head translation: 13.9mm (B) Global lordosis (+kyphotic/-lordortic): $-22.9^{\circ}$ (C) Regional lordosis (+kyphotic/-lordortic): $3.5^{\circ}$

performed on the posterior cervical fascia, nuchal line of occiput, rectus sheath, sturnum fascia, superficial cervical fascia, upper trapezius, superior angle of the scapular, and sulcus between the deltoid and pectoralis major.

The patient was educated to perform self-stretching for the area of sub-hyoid once a day. She received 18 treatments three times a week from January 4, 2018 to February 14, 2018.

\section{Results}

\section{Chief Complain and Goal}

After treatment, she achieved the treatment goal as the study time increased from one hour to two hours. The feeling of swelling into the upper trapezius disappeared, but after 2 hours of study, persistent pain with a level of RAS 6 and a stiff feeling in front of the neck were reported. She still had pain with a level of RAS 1 while resting.

\section{Motion test}

The patient did not experience the pain that she had previously occurred at the posterior neck and scapular inner border with some of neck motion.

\section{Cervical posture}

After treatment, her AHT was decreased from $13.9 \mathrm{~mm}$ to $0.3 \mathrm{~mm}$. The global lordosis improved from $-22.9^{\circ}$ to $-24.4^{\circ}$, and the regional lordosis was improved from $3.5^{\circ}$ to $-3.8^{\circ}$. In addition, neuroforaminal encroachment between C4 and C5 was not detected after treatment (Fig. 2, Table 1).

\section{Discussion}

The fascia maintains its form in the body as well as tension and elasticity by transmission and preservation for power. This not only receives and transmits stimulus information but also transfers moisture and nutrition by engaging in the metabolism [6].

Gauns and Guruput [7] divided randomly 40 people, who had mechanical neck pain and were aged between 


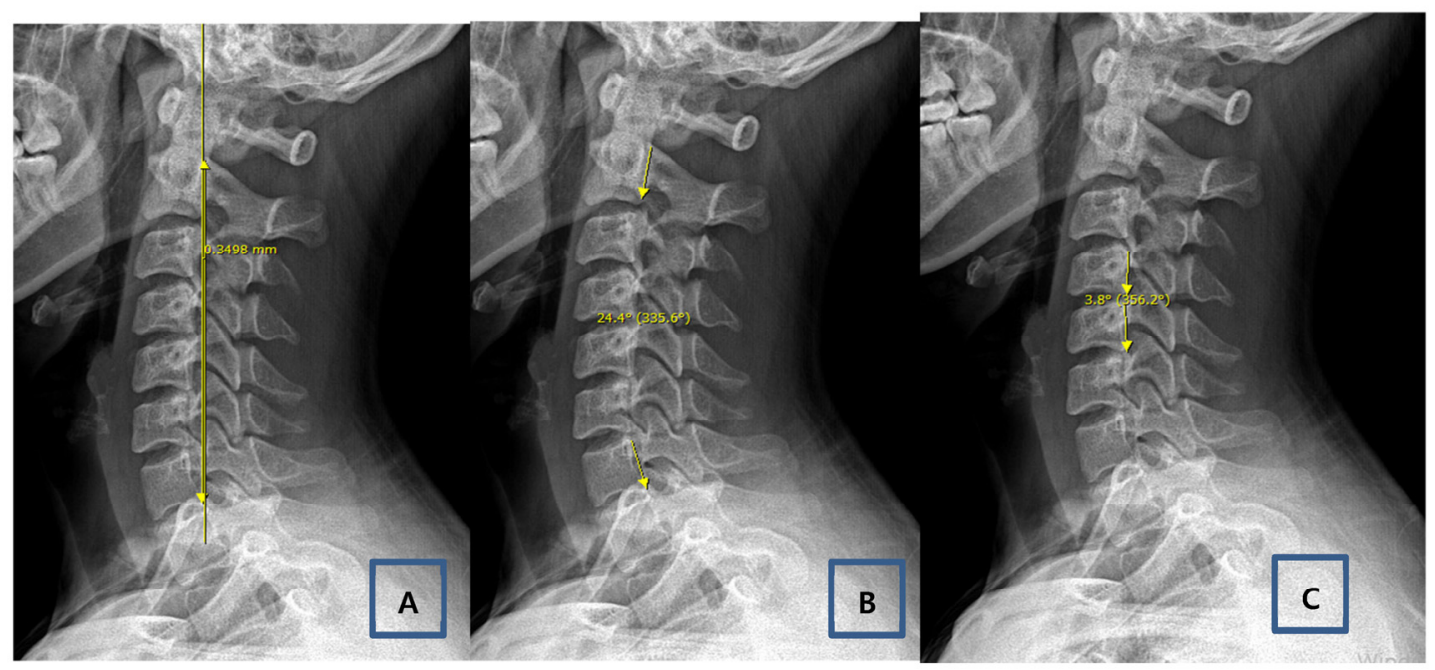

Fig. 2. Lateral projection of a cervical spine radiograph after MFR.

(A) Anterior head translation: 0.3mm (B) Global lordosis (+kyphotic/-lordortic): $-24.4^{\circ}$ (C) Regional lordosis (+kyphotic/-lordortic): $-3.8^{\circ}$

Table 1. Values of Cervical Alignment before and after MFR. $\mathrm{AHT}^{\mathrm{a}}$ Global Lordosis Regional Lordosis

\begin{tabular}{cccc}
\hline Pre-test & $13.9 \mathrm{~mm}$ & $-22.9^{\circ}$ & $3.5^{\circ}$ \\
\hline Post-test & $0.3 \mathrm{~mm}$ & $-24.4^{\circ}$ & $-3.8^{\circ}$ \\
\hline Difference (Post-pre) & $-13.6 \mathrm{~mm}$ & $-1.5^{\circ}$ & $-7.3^{\circ}$ \\
\hline
\end{tabular}

${ }^{\mathrm{a}}$ AHT(Anterior Head Translation)

20 and 50 years, into two groups. The control group pe rformed conservative treatment of a thermo-weather pack, percutaneous electrical stimulation, stretching, and strengthening exercises. The experimental group performed gross MFR treatment continuously on the neck and upper extremity for six days. The control group showed an improvement in pain and the range of motion for flexion and rotation of the neck except for flexion endurance. The experimental group showed significant improvement in pain and the range of motion for flexion and rotation of the neck compared to the control group, and the flexion endurance of the neck was increased. Because the muscle surrounding the fascia is linked to a tendon, most of the strength may depend on the fascia health [6]. The increase in neck flexor endurance in the experimental group and more improvement of pain and the range of motion compared to the control group can be attributed to an improvement of muscle performance due to the improved fascia fitness.

In the present study, after treatment, the patient reported no pain during neck motion. The possible study time without pain was increased because MFR puts the fascia in good condition, which would improve the activity of the muscle around the neck.

Caneiro et al. [8] reported that when the same subject underwent the anterior head translation posture, the neck extensor showed more activity than at the neutral head posture. Peolsson et al. [9] recounted that when the same 
subject underwent flexed posture $\left(30^{\circ}\right.$ of lower cervical flexion) and forward head posture ( $30^{\circ}$ of lower cervical flexion followed by extension of the upper cervical spine), the upper trapezius, splenius, semispinalis capitis, semispinalis cervicis, and multifidus showed significantly greater muscle deformation than at the neutral posture. In addition, the muscle deformation at the flexed posture was more than that at the forward head posture.

Nimbarte et al. [10] found increased upper trapezius activity during the lifting of low loads when performed in a maximally flexed neck posture compared to lifting in a neutral posture.

To explain the correlation between posture, pain, and muscle strength, the length-tension relationship is generally mentioned. In this paper, the patient complained of pain with a level of RAS 6 after approximately two hours of study even after treatment. This is possibly because the patient adopted the flexed posture of the neck to look down while studying. This should lead to more activity of the neck extensor, particularly the upper trapezius, because of the unsuitable length of the muscle and the effects of the head weight due to gravity. Therefore, the therapist should advise the patient to adopt an appropriate posture.

Fortner et al. [11] presented a 38-year-old male with advanced spinal osteoarthritis at the cervical area, who received cervical extension traction, extension exercise, and spinal manipulation to improve the cervical lordosis. As a result, the neck pain and grip strength improved along with increased global cervical lordosis. In this paper, after applying MFR, the global lordosis improved slightly $\left(1.5^{\circ}\right)$, whereas the regional lordosis improved greatly $\left(7.3^{\circ}\right)$ from kyphosis ( $3.5^{\circ}$ in ARA) to lordosis $\left(-3.8^{\circ}\right.$ in ARA). In addition, the neural foraminal encroachment that existed before applying MFR disappeared on the radiograph taken after applying MFR. MFR may remove the limitation of soft tissues, producing a traction effect that alters the cervical alignment. The effects of MFR in this patient cannot be generalized to all patients with neck pain, but this paper clearly showed that the MFR approach in the cervical area results in realignment and elongation.

\section{Conclusion}

This paper described the effects of the MFR approach in a 20-year-old woman with neuroforaminal encroachment who visited the hospital with neck pain. After applying MFR, the neck pain at rest decreased from RAS2 to RAS1, and the possible study time was increased from one to two hours. On the other hand, the improvement of pain during study (RAS 7 in pre-applied MFR and RAS 6 in Post- applied MFR) was insufficient. Motion in all directions of the neck should be possible without increasing the level of pain. AHT and cervical global and regional lordosis were improved. MFR may help improve the alignment of the cervical spine and the pain related to the motion of the neck.

\section{References}

[1] Scheer JK, Tang JA, Smith JS, et al. Cervical spine alignment, sagittal deformity, and clinical implications: a review. J Neurosurg Spine. 2013;19:141-59.

[2] Talekar KS, Cox M, Smith E, Flanders AE. Imaging spinal stenosis. Appl Radiol. 2017;46(1):8-17.

[3] Murphy DR, Coulis CM, Gerrard JK. Cervical spondylosis with spinal cord encroachment: should preventive surgery be recommended? Chiropr Osteopat. 2009;17:8.

[4] Smith J. Stnktural Bodywork, Hanmi Medical Publishing Co., 1st ed. 2011:147-8.

[5] Lippa L, Lippa L, Cacciola F. Loss of cervical lordosis: What is the prognosis? J Craniovertebr Junction Spine. 2017;8(1):9-14.

[6] Schleip R. Fascial fitness, Yeong Mun Publishing Co., 1st ed. 2019:59.

[7] Gauns SV, Gurudut PV. A randomized controlled trial to study the effect of gross myofascial release on 
mechanical neck pain referred to upper limb. Int J Health Sci. 2018;12(5):51-9.

[8] Caneiro JP, O sullivan P, Burnett A, et al. The influence of different sitting postures on head/neck posture and muscle activity. Manual Therapy. 2010;15(1):54-60.

[9] Peolsson A, Marstein E, McNamara T, et al. Does posture of the cervical spine influence dorsal neck muscle activity when lifting? Man Ther. 2014;19(1):32-6.

[10] Nimbarte AD, Aghazadeh F, Ikuma LH, et al. Neck disorders among construction workers: understanding the physical loads on the cervical spine during static lifting tasks. Ind Health. 2010;48(2):145-53.

[11] Fortner MO, Oakley PA, Harrison DE. Non-surgical improvement of cervical lordosis is possible in advanced spinal osteoarthritis: a CBP® case report. J Phys Ther Sci. 2018;30(1):108-12. 